\title{
Antibiotic Sensitivity of High Vaginal Swabs from Asymptomatic Pregnant Women
}

\author{
Abdulrazzaq Bahaulddin Mohammed(MSc) ${ }^{1}$, Haval Abdulkhalik \\ Hamadamin $(\mathrm{MSc})^{2}$, Alla'a Miyasar Ahmed (MSc) ${ }^{3}$ \\ ${ }^{1}$ College of Medicine, Hawler Medical University,Erbil, Iraq \\ ${ }^{2}$ College of Medicine, Hawler Medical University,Erbil, Iraq \\ ${ }^{3}$ College of Medicine, Hawler Medical University,Erbil, Iraq \\ Correspondence Address: \\ Dr. Abdulrazzaq Bahaulddin Mohammed \\ College of Medicine, Hawler Medical University,Erbil, Iraq \\ email: abdulrazaq.muhammed@HMU.edu.krd mobile 07508434824
}

Received: 3 November 2020

Revised: 9 November 2020

Accepted: 13 December 2020

Published: 15 April 2021

Diyala Medical Journal 2021:20(1): 70- 75

\section{Abstract}

Background: Vaginal microbiota considered as a complex microbial population consisting of a multitude of microbial species and causes many vaginal infections including bacterial vaginosis.

Objective: The study is investigating the antibiotic sensitivity of predominant vaginal microbiota.

Patients and Methods: 250 pregnant women in Erbil city in the North of Iraq, from October 2018 to March 2019. Samples were collected from pregnant women who visited Maternity, Rizgary and Raparin Hospitals' laboratory department under medical precautions. The samples were cultures to investigate to identify the bacteria types and sensitivity for common antibiotics.

Results: About $72 \%$ of samples showed positive microbial growth and the higher distribution percentage of isolated microorganisms was $27.2 \%, 23.8 \%, 21.6$ and $11.6 \%$ for Candida sp., Staphylococcus aureus, Escherichia coli and Streptococcus pyogenes respectively. Moreover, antibiotic sensitivity tests declared that ciprofloxacin was effectively inhibited the growth of both Staphylococcus aureus and Streptococcus pyogenes while Norfloxacin was 95\% which inhibited the growth of E. coli.

Conclusion: Candida albicans, Staphylococcus aureus, Escherichia coli and Streptococcus pyogenes are among the most predominant microorganisms in pregnant women.

Keywords: Antibiotic sensitivity profile, Bacterial culture, High vaginal swab 


\section{Introduction}

The vaginal microbiota has been identified over 150 years ago with the innovation of light microscopy and bacterial cultures. The vaginal area is considered a complex microbial environment thatharbors a multitude of microbial species[1]. The term, "bacterial vaginosis," was chosen to describe abnormal bacterial presence in the vagina which is characterized by an overgrowth of anaerobic bacteria[2]. About $75 \%$ of women have risks of vaginal infections at least one time during their lifetime and the vaginal tract can be infected by common pathogens including Enterobacteriaceae $s p$., Enterococcus sp., $\quad$ Streptococcus $s p$., Staphylococcus sp., Lactobacillus sp., and Candida albicans [1,3]. Numerous factors may contribute to changes in the vaginal environment, including antibiotic administration and it has been confirmed that using treatment without performing a susceptibility test might be a reason behind increasing resistance patterns[4]. Additionally, Staphylococcus sp. was found in virtually $100 \%$ of women who have toxic shock syndrome and Group B Streptococci was isolated from $5 \%$ to $25 \%$ of the vaginal cultures of healthy women[5]. Thus, Staphylococcal flora of the female genital tract and Streptococcal population of the vagina is of special interest which investigated by many studies as these pathogens may also cause neonatal sepsis in pregnant women [6-8] . The present study aimed to determine the antibiotic sensitivity profile of predominant vaginal bacteria such as Staphylococcus sp., Escherichia coli and Streptococcus sp. in Erbil City (Kurdistan Region of Iraq), due to the lack of surveillance data in general practice.

\section{Patients and Methods}

\section{Sample collection}

Totally, 250 pregnant women at different gestation periods were enrolled in the present study, all women were attending the laboratory of (Maternity, Raparin and Rizgary hospital) and they were none smokers and aged between 22-34 years (mean= 27 years). There was no history of symptoms of genital tract infections or recent use of any antibiotics. High vaginal swabs were obtained from each of the pregnant women by specialized gynecologists.

\section{Isolation and Identification}

Diagnosis of bacterial isolated conducted with the aid of standard microbiological techniques, the swabs were streaked onto blood agar, Sabouraud-dextrose agar, MacConkey agar and chocolate agar plates in two replications for minimizing the rate of contamination. The inoculated plates were incubated separately in two groups of aerobic and anaerobic conditions for 20-24 hours and 72 hours, respectively, at $37{ }^{\circ} \mathrm{C}$, the process of identification further confirmed by Gram staining techniques for subgrouping the colonies into Gram negative and Gram positive groups[9].

\section{Antibiotic Sensitivity Profile}

Staphylococcus aureus, Escherichia coli, and Streptococcus pyogenes isolates were prepared and subjected to antimicrobial susceptibility using the Kirby-Bauer disc diffusion method on Muller-Hinton Agar and four groups of antibiotics used to determine the sensitivity profile of Staphylococcus aureus, Streptococcus pyogenes[10] and 
Escherichia coli which were (Penicillin group, Cephalosporins, Quinolones, and Aminoglycosides), however, two antibiotics from each group examined. Finally, results were interpreted according to the Clinical Laboratory Standard Institute to interpret the diameter of the inhibition zone (CLSI) [1012].

\section{Statistical analysis}

In the present study, the general formula of percentage was used for calculating the percentage of each microorganism in high vaginal swabs depends on the value of identified frequency for each microorganism and the used formula was (percentage = frequency / total value) and finally the obtained value multiplied by 100 for obtaining the exact percentage. However, the sensitivity profile determined for each microorganism by using the Kirby Bauer approach which depends on the diameter of the inhibition zone and the concentration of used antibiotics.

\section{Results}

A total of 180 specimens showed positive microbial growth out of 250 which represent (72\%) prevalence rate of vaginal infections, and for easy data expression every specimen selected only for one microorganism growth and positive microbial growth has been distributed into three groups according to microbiological identification methods including (Growth conditions, Selective media, and Microscopically examinations). Details about the distribution of isolated microorganisms from vaginal swabs have been shown in Table (1), the higher distribution percentage of isolated microorganisms was $27.2 \%$ for fungal (Candida spp.), while Staphylococcus aureus showed a higher frequency percentage among isolated bacteria which was $23.8 \%$ and followed by 21.6 and $11.6 \%$ for both Escherichia coli and Streptococcus pyogenes, respectively.

Table (1): Distribution of identified microorganisms in High Vaginal Swabs

\begin{tabular}{|c|c|c|c|}
\hline Microorganisms & Species & Frequency & Percentage \\
\hline \multirow{3}{*}{ Gram positive } & Staphylococcus aureus & 43 & 23.8 \\
\hline & Streptococcus pyogenes & 21 & 11.6 \\
\hline & Fusobacterium spp & 3 & 1.6 \\
\hline \multirow{3}{*}{ Gram negative } & Escherichia coli & 39 & 21.6 \\
\hline & Klebsiella pneumoniae & 5 & 2.7 \\
\hline & Pseudomonas aeruginosa & 20 & 11.1 \\
\hline Fungal (yeast) & Candida spp. & 49 & 27.2 \\
\hline
\end{tabular}

The highest sensitivity test declared that Staphylococcus aureus isolates were highly sensitive to Ciprofloxacin $100 \%$ and Amikacin $80.4 \%$, while Streptococcus pyogenes isolates were highly sensitive to Ciprofloxacin $100 \%$, Amoxicillin 94.1 and Gentamycin $86.1 \%$; however, lowest antibiotic sensitivities were showed by both Staphylococcus aureus and Streptococcus pyogenes against Ampicillin by the percentage of $20.2 \%$ and $0 \%$, respectively. $E$. coli isolated from high vaginal swabs showed high sensitivity to Norfloxacin $95 \%$ and Amikacin $90 \%$, while showed low sensitivity against Amoxicillin and Ampicillin by percentage of 18.2 and $0 \%$, respectively as shown in Table (2). 
Table (2): Sensitivity profile of isolated Staphylococcus aureus, Streptococcus pyogenes and Escherichia coli) from asymptomatic pregnant women

\begin{tabular}{|c|c||c||c|c|}
\hline Antibiotics & $\begin{array}{c}\text { Concentration } \\
\text { Microgram }\end{array}$ & $\begin{array}{c}\text { Staphylococcu } \\
\text { s aureus }\end{array}$ & $\begin{array}{c}\text { Streptococcus } \\
\text { pyogenes }\end{array}$ & Escherichia coli \\
\hline \hline Ampicillin (AMP) & 25 & 20.2 & 0 & 18.2 \\
\hline \hline Amoxicillin & 25 & 25 & 94.1 & 0 \\
\hline \hline Cephradine & 5 & 29.2 & 26.2 & 33.3 \\
\hline \hline Ceftazidime & 30 & 82 & 60.2 & 70.6 \\
\hline \hline Norfloxacin & 10 & 69.5 & 70 & 95 \\
\hline \hline Ciprofloxacin & 5 & 100 & 100 & 40 \\
\hline \hline Gentamycin & 10 & 70.3 & 86.1 & 45.9 \\
\hline \hline Amikacin & & 80.4 & 44.4 & 90 \\
\hline
\end{tabular}

\section{Discussion}

Candida albicans was the most prevalent microorganisms isolated in high vaginal swabs according to the present study. This finding is in line with the previous study which reported the same results from vaginal culture from asymptomatic pre-pubertal girls(13). However, another study concluded that vaginal candidiasis commonly present among premenopausal woman [14].

In the present study, Staphylococcus aureus was predominant vaginal isolates among the bacterial group by $23.8 \%$ which followed by Escherichia coli $21.6 \%$ and Streptococcus pyogenes $11.6 \%$, among asymptomatic pregnant women aged between 22-34 years. This finding agrees with the previous investigation which reported that Staphylococcus aureus was the most prevalent vaginal pathogen and its highest prevalence was noted at 31-40 years[15].

Additionally, another study reported that Staphylococcus aureus was most prevalent than Escherichia coli in vaginal swabs[16]. This result does not agree with the previous findings which reported that $E$. coli by $34.5 \%$ while Staphylococcus aureus by $20.8 \%$ in vaginal swabs of pregnant women[17]. Other studies also well reported that vaginal pathogens are more commonly present in adult pregnant women [16,17]. Ciprofloxacin is classified in an organic acid antimicrobial category which has a very broad spectrum of activity and the primary mechanism action of ciprofloxacin is blocking replication of bacteria through inhibiting DNA gyrase[18]. In the present study, the results of antibiotics sensitivity confirmed that Staphylococcus aureus and Streptococcus pyogenes were very sensitive $100 \%$ for Ciprofloxacin. This result is in line with previous finding which reported that ciprofloxacin inhibits the growth of both broad spectrum of bacteria including E. coli 'Staphylococcus aureus and Streptococcus pyogenes also reported that only $37(0.6 \%)$ isolates showed resistance to Ciprofloxacin among 5,994 isolates. Norfloxacin is structurally related to Nalidixic acid, but it has a broader in vitro antibacterial spectrum and is generally more active. In the present study, Escherichia coli vaginal isolates were very sensitive $95 \%$ to Norfloxacin. This result is similar to other studies which concluded that low concentration of Norfloxacin $2 \mathrm{mg} / \mathrm{L}$ inhibits the growth of most Gram-negative pathogens including $E$. coli and Klebsiella, Enterobacter, Proteus and Citrobacter species[19]. The lowest antibiotic 
sensitivities were showed by both Staphylococcus aureus and Streptococcus pyogenes against Ampicillin by percentages of $20.2 \%$ and $0 \%$, respectively. E. coli showed low sensitivity against Amoxicillin and Ampicillin by percentages of $18.2 \%$ and $0 \%$, respectively. Many studies determined that acquiring antibiotic resistances due to numerous factors including antibiotic uses without physician prescription and it has been confirmed that using treatment without performing susceptibility test might be an important factor behind increasing antibacterial resistance[4].

\section{Conclusions}

Candida albicans, Staphylococcus aureus, Escherichia coli and Streptococcus pyogenes are among the most predominant microorganisms in pregnant women. Ciprofloxacin was very effective against Staphylococcus aureus and Streptococcus pyogenes which inhibited their growth $100 \%$ while Norfloxacin was inhibited the growth of E. coli by $95 \%$.

\section{Recommendations}

Microbiology laboratories should use standardized methods and follow published guidance for determining antimicrobial susceptibility of targeted multi-drug resistant organisms. Its preferable to establish systems that ensure these laboratories notify control staff when a novel resistant pattern is detected.

Source of funding: The authors received no specific funding for this work.

Ethical clearance: Ethical clearance was granted to the researchers by ethics committee at the College of the Health Sciences /Hawler medical University.
Conflict of interest: Researchers declare no conflict of interest.

\section{References}

[1]Martin DH. The microbiota of the vagina and its influence on women's health and disease. Am J Med Sci. 2012;343(1):2-9.

[2] Faro S, Martens M, Maccato M, Hammill $\mathrm{H}$, Pearlman M. Vaginal flora and pelvic inflammatory disease. Am J Obstet Gynecol. 1993;169(2):470-4.

[3]Yadav SK, Jain GK, Mazumder A, Khar RK. Antimicrobial activity of a novel polyherbal combination for the treatment of vaginal infection. J Adv Pharm Technol Res. 2019;10(4):190.

[4]Stokholm J, Schjørring S, Eskildsen CE, Pedersen L, Bischoff AL, Følsgaard N, et al. Antibiotic use during pregnancy alters the commensal vaginal microbiota. Clin Microbiol Infect. 2014;20(7):629-35.

[5]Gibbs RS. Microbiology of the female genital tract. Am J Obstet Gynecol. 1987;156(2):491-5.

[6]Weinstein L. The bacterial flora of the human vagina. Yale $J$ Biol Med. 1938;10(3):247.

[7]Ruíz FO, Gerbaldo G, García MJ, Giordano W, Pascual L, Barberis IL. Synergistic effect between two bacteriocinlike inhibitory substances produced by lactobacilli strains with inhibitory activity for Streptococcus agalactiae. Curr Microbiol. 2012;64(4):349-56.

[8]Roca A, Bojang A, Camara B, Oluwalana $\mathrm{C}$, Lette $\mathrm{K}$, West $\mathrm{P}$, et al. Maternal colonization with Staphylococcus aureus and Group B streptococcus is associated with colonization in newborns. Clin Microbiol Infect. 2017;23(12):974-9. 
[9]Demilie T, Beyene G, Melaku S, Tsegaye W. Urinary bacterial profile and antibiotic susceptibility pattern among pregnant women in North West Ethiopia. Ethiop J Health Sci. 2012;22(2).

[10]Institute CLS. Performance standards for antimicrobial susceptibility testing. Fifteenth Informational Supplement. CLSI/NCCLS document M100-S15. Clinical and Laboratory Standards Institute Wayne, PA, USA; 2005.

[11]Cowan ST, Steel KJ. Manual for the identification of medical bacteria. Man Identif Med Bact. 1965.

[12]Levinson W. Klebsiella in: Medical Microbiology \& Immunology examination \& Broad review 8th ed. USA. 2004

[13]Joishy M, Ashtekar CS, Jain A, Gonsalves R. Do we need to treat vulvovaginitis in prepubertal girls? BMJ. 2005;330(7484):186-8.

[14]Jacobsen SM, Stickler DJ, Mobley HLT, Shirtliff ME. Complicated catheterassociated urinary tract infections due to Escherichia coli and Proteus mirabilis. Clin Microbiol Rev. 2008;21(1):26-59.

[15]Mumtaz S, Ahmad M, Aftab I, Akhtar N, ul Hassan M, Hamid A. Aerobic vaginal pathogens and their sensitivity pattern. J Ayub Med Coll Abbottabad. 2008;20(1):113-7.

[16]Fan A, Yue Y, Geng N, Zhang H, Wang Y, Xue F. Aerobic vaginitis and mixed infections: comparison of clinical and laboratory findings. Arch Gynecol Obstet. 2013;287(2):329-35.

[17]Orish VN, Ofori-Amoah J, François M, Silverius BK, Mensah EK. Microbial and Antibiotic Sensitivity Pattern of High Vaginal Swab Culture Results in Sekondi-
Takoradi Metropolis of the Western Region of Ghana: Retrospective Study. Eur J Clin Biomed Sci. 2016;2(5):45-50.

[18]Hooper DC, Wolfson JS, Ng EY, Swartz MN. Mechanisms of action of and resistance to ciprofloxacin. Am J Med. 1987;82(4A):12-20.

[19]Mishra MP, Debata NK, Padhy RN. Surveillance of multidrug resistant uropathogenic bacteria in hospitalized patients in Indian. Asian Pac J Trop Biomed. 2013;3(4):315-24. 